\title{
The effects of seasons and weather on sleep patterns measured through longitudinal multimodal sensing
}

\author{
Stephen M. Mattingly (iD) ${ }^{1 凶}$, Ted Grover ${ }^{2}$, Gonzalo J. Martinez (iD), Talayeh Aledavood ${ }^{3}$, Pablo Robles-Granda (iD ${ }^{1}$, Kari Nies ${ }^{2}$, \\ Aaron Striegel ${ }^{1}$ and Gloria Mark ${ }^{2}$
}

Previous studies of seasonal effects on sleep have yielded unclear results, likely due to methodological differences and limitations in data size and/or quality. We measured the sleep habits of 216 individuals across the U.S. over four seasons for slightly over a year using objective, continuous, and unobtrusive measures of sleep and local weather. In addition, we controlled for demographics and trait-like constructs previously identified to correlate with sleep behavior. We investigated seasonal and weather effects of sleep duration, bedtime, and wake time. We found several small but statistically significant effects of seasonal and weather effects on sleep patterns. We observe the strongest seasonal effects for wake time and sleep duration, especially during the spring season: wake times are earlier, and sleep duration decreases (compared to the reference season winter). Sleep duration also modestly decreases when day lengths get longer (between the winter and summer solstice). Bedtimes and wake times tend to be slightly later as outdoor temperature increases.

npj Digital Medicine (2021)4:76; https://doi.org/10.1038/s41746-021-00435-2

\section{INTRODUCTION}

Sleep is vital to health ${ }^{1-4}, \operatorname{mood}^{5-9}$, cognitive performance $e^{10-12}$ work quality ${ }^{13-16}$, and social life ${ }^{17-20}$. Given the importance of sleep, many contributing factors to sleep have been identified, including (but not limited to) mood ${ }^{21,22}$, personality ${ }^{23,24}$, sleep quality $^{25,26}$, chronotype ${ }^{18,27-29}$, and demographic information such as age, sex, income ${ }^{30-35}$, and homeostatic sleep need (for a review, see refs. ${ }^{36,37}$ ).

Sleep behavior is influenced by circadian processes, i.e., in a 24h cycle ${ }^{38-44}$. Circadian systems rely on internal timekeeping cells ${ }^{44}$. These "clock cells" synchronize with the environment via "zeitgebers" 45 or "time clues" such as light and ambient temperature and serve as a circadian pacemaker to coordinate other circadian responses to optimize to the environment ${ }^{46-53}$, e.g., in humans to promote sleep when it is dark and to be awake when it is light, to be asleep at the lowest point of core body temperature ${ }^{43,54-56}$, and/or to avoid extremes in ambient temperature that can impair sleep ${ }^{57-61}$. The circadian pacemaker changes body temperature ${ }^{43,60,62,63}$ and melatonin ${ }^{64-66}$, a hormone that promotes and maintains sleep, to assist in sleep regulation and wake cycles. In animal models, this pacemaker can adjust seasonally, in general increasing wake duration during longer periods of light and warmer temperatures (e.g., summer) and decreasing wake duration during periods with less light and lower temperatures (e.g., winter) ${ }^{67-72}$. In humans, it is clear that artificial light interacts with circadian systems ${ }^{73-76}$ (for a review, see Duffy and Wright ${ }^{52}$, but it is unclear if artificial light suppresses $^{77}$ or interacts ${ }^{78}$ with seasonal variations in circadian mechanisms, and further, if these effects result in observed seasonal variations in sleep parameters such as sleep duration ${ }^{79}$.

Thus, in real-world environments with artificial light, it is not clear whether seasonal variations would affect sleep. In fact, studies examining seasonal effects on sleep have produced mixed findings. While few laboratory studies explicitly examine seasonality in humans, Wehr et al. ${ }^{77}$ asked 21 males (between ages 20 and 50) to record light exposure and sleep three days prior to an experimental study that gathered body temperature and hormone samples in the winter and the summer. Light sensors detected seasonal differences, but no effect of season was found on sleep duration or melatonin secretion. In a similar study, Honma et al. ${ }^{79}$ studied ten males (between ages 20 and 28) in an experimental living facility for 4 days each season with environmental control, sleep measurement, and exposure to natural light. They report no effect of season on sleep duration, but report earlier sleep onset and offset in winter compared to summer.

Studies using wearable sensors use objective measures but generally small sample sizes over brief periods and also have demonstrated ambiguous seasonal effects. For instance, O'Connell et al. ${ }^{80}$ used wearables and sleep diaries to track sleep for 1 week each season with 46 adults, and report no significant seasonal effects, while Lehnkering and Siegmund ${ }^{81}$ found that participants slept longer in autumn than in spring, with no seasonal effects on the bed or wake time with 34 participants for 15 days in spring and autumn. In preindustrial societies, De la Iglesia et al. ${ }^{74}$ examined 44 participants in hunter-gatherer tribes with and without access to electricity for one week in summer and/or winter. They report longer sleep durations in winter for both groups, but no differences in bedtime between seasons. When collapsing across both groups, they report a later wake time in summer. With 72 participants in three preindustrial societies examined between 8 and 28 days in summer and winter, sleep duration was found to be longer in winter, with earlier bedtimes and wake times in winter compared to summer (Yetish et al. ${ }^{82}$ ). Small seasonal effects on sleep duration have been reported in 8-11-year-olds measured for 7 days in three seasons ${ }^{83}$ and in 50-64-year-olds (but not 64-75 year-olds or $75+$ year-olds) ${ }^{58}$, with each person measured one week but in different seasons. Participants' data were then combined to calculate the seasonal effects.

\footnotetext{
${ }^{1}$ Department of Computer Science \& Engineering, University of Notre Dame, Notre Dame, IN, USA. ${ }^{2}$ Department of Informatics, University of California, Irvine, CA, USA. ${ }^{3}$ Department of Computer Science, Aalto University, Espoo, Finland. ${ }^{凶}$ email: smattin1@nd.edu
} 
Self-report and data repository studies (e.g., Centers for Disease Control Behavioral Risk Factor Surveillance System, http://www. cdc.gov/brfss) tend to be much larger and generally do show seasonal effects, at least for some subgroups, though they often lack bed and wake time data. For instance, Allebrandt et al. ${ }^{28}$ evaluated health records of 9765 participants and found that evening chronotypes had seasonal variability in sleep duration, but morning chronotypes did not. Using survey and meteorological data ${ }^{57}$, found that participants showed a higher rate of insufficient sleep in summer on anomalously warm nights, especially for low SES and those older than 65, but otherwise no seasonal effects. Comparing sleep in different latitudes, Friborg et al. ${ }^{84}$ collected sleep diaries of 330 adults for 1 week in summer and winter from Ghana (where day length increases $0.3 \mathrm{~h}$ from winter to summer), and Norway (which increases $11.7 \mathrm{~h}$ ). No seasonal effects were observed for Ghanaians, while Norwegians had later bed and wake times on summer weekdays (but not weekends) with no significant difference in sleep duration. Thorleifsdottir et al. ${ }^{85}$ followed 668 children for 10 years who kept sleep diaries. The youngest children showed longer sleep, earlier bedtimes, and later wake times in winter compared to spring. Effects weaken with age, e.g., significant seasonal effects on sleep duration for those under 5 years old, while on weekends only for those aged 5-10, and none for older than 10 years old. This is mirrored by parental surveys about 9-12-year-old children in the $U S^{86}$, in which parents endorsed that their children slept more in winter, especially for girls. These effects were more prevalent in northern compared to southern latitudes and were reduced for older relatives to younger children. Nonwearable large-scale sensor studies also demonstrate seasonal effects. For instance, data from the "Sleep Cycle" app ${ }^{87}$ demonstrated teens sleep more in summer (possibly due to a break from school), and that young adults showed longer sleep durations in the winter relative to summer. Japanese users of a biomotion sensor demonstrated seasonal effects on wake time, with later wake times in winter than in summer, especially for weekends ${ }^{88}$. Using call records, longer sleep durations were found in winter, with more variability based on latitude ${ }^{34}$.

In sum, if seasonal effects are detected, sleep is found to be longer in winter and shorter in summer, likely due to increased day length and/or increased temperature, and with effects being particularly pronounced in children or the elderly $57,58,83,85,87,89$, preindustrial societies ${ }^{74,82}$, or in the absence of artificial light ${ }^{73}$, though these trends may interact with school or work demands (see refs. ${ }^{58,85,87}$ ).

The lack of clarity in results is likely due to methodological differences and study limitations. Differences between study settings (e.g., laboratory vs. observational, industrial vs. preindustrial), the choice of datasets (wearable, self-report, and cell phone data), and the population studied (close vs. far from the equator, children vs. adults, and evening vs. morning chronotypes) may contribute to why sleep factors are found to be significantly different due to seasonal effects. Some studies only examine a small time window, such as one to 2 weeks per season ${ }^{74,80,81,83}$, and thus may lack the temporal resolution to detect seasonal effects, especially for fall and spring. Large-scale studies tend to rely on self-report ${ }^{57,58,85}$, which can be subject to memory biases or are collected from short time windows aggregated across many years $28,57,58,85,90$. The effects found in laboratory studies may not be observable in day-to-day life, may not generalize to preindustrial settings, or may only apply to specific subgroups or cultures ${ }^{79,90-92}$. Furthermore, seasons may have weather effects that affect sleep, e.g., snow, cloudy days, or rain (see Rifkin et al. ${ }^{93}$ for a meta-analysis), yet prior work on seasonal effects does not address variations in weather that are associated with seasons.

The goal of the current study is to investigate the detailed effects of seasons and weather on sleep by countering the methodological limitations of past studies. We investigated different parameters of daily sleep habits (sleep duration, bedtime, and wake time). What differentiates our study from nearly all of the past sleep studies shown in Table 1 is the use of objective, continuous, and longitudinal measures of sleep. Using wearable devices, we measured the in-situ sleep habits of 216 individuals across the U.S. across four seasons using daily monitoring of sleep and localized environmental measures, while controlling for a range of trait-like constructs previously identified to correlate with sleep behavior. Other than temperature, most weather features have been overlooked by other studies, while we were able to collect daily localized weather. This comprehensive approach allowed us to determine whether seasons and weather influence sleep in the industrial world and at the same time provides a more unifying perspective about sleep that is contextualized with respect to previous studies.

\section{RESULTS}

\section{Participants}

After controlling for missing data (see "Methods" section), we used a final dataset of 51,836 entries of sleep data from 216 participants. Table 2 presents a full summary of demographic and psychological trait statistics for our final participant set, and Fig. 1 shows the geospatial distribution of our participants across the USA. Figure 2 presents the average sleep duration (Fig. 2a), bedtime (Fig. 2b), and wake time (Fig. 2c) over the year-long study duration. Averages in Fig. 2 were calculated from those participants who had the data for each month. Thus, the participant composition across each month may vary slightly. To ensure that the variability in the number of samples across seasons does not explain the differences between seasons, we verified that there was an approximately uniform distribution of daily observations.

\section{Sleep duration}

The sleep duration results for each of the nested models are presented in Table 3.

In the full model including demographic, psychological traits, seasonal and weather variables (Model 3), only day length and spring season were statistically significantly associated with sleep duration (Table 3), with a fixed-effect variance explained (pseudo$R^{2}$ ) of 0.02 and conditional variance explained (pseudo- $R^{2}$ ) of 0.16 . The intraclass correlation coefficient (ICC) for the full model was 0.14 , indicating that the random effects of participants explained $\sim 14 \%$ of the total variance explained by the model. The unstandardized beta coefficients of this model (Table 3 ) show that sleep duration decreases with increases in day length, and every extra hour of day length associated with a decrease in sleep duration of $3.6 \mathrm{~min}(95 \%$ C.I. $(-2.4,-4.8), P<.001)$. In addition, spring was associated with a sleep duration that decreased by 12.6 min (95\% C.I. $(-16.8,-8.4), P<.001)$ (compared to the reference season winter). In comparing all three models, the results suggest that demographic, psychological traits, seasonal, and weather variables explained little of the variance in sleep duration in our data. Using one-sided $F$-tests for variance comparison between the models, we saw that the seasonal model (Model 2) explains significantly more variance in sleep duration than the model with demographics and psychological traits $(F=166.09, P<0.001)$, and the addition of weather variables (temperature, wind, and humidity/cloud cover) in the full model (Model 3) did not explain significantly more variance over Model 2 , which includes seasonal variables $(F=1.22, P=0.30)$. The seasonal model (Model 2 ) had the lowest BIC value of all models tested indicating that it was the best-fitting model. 


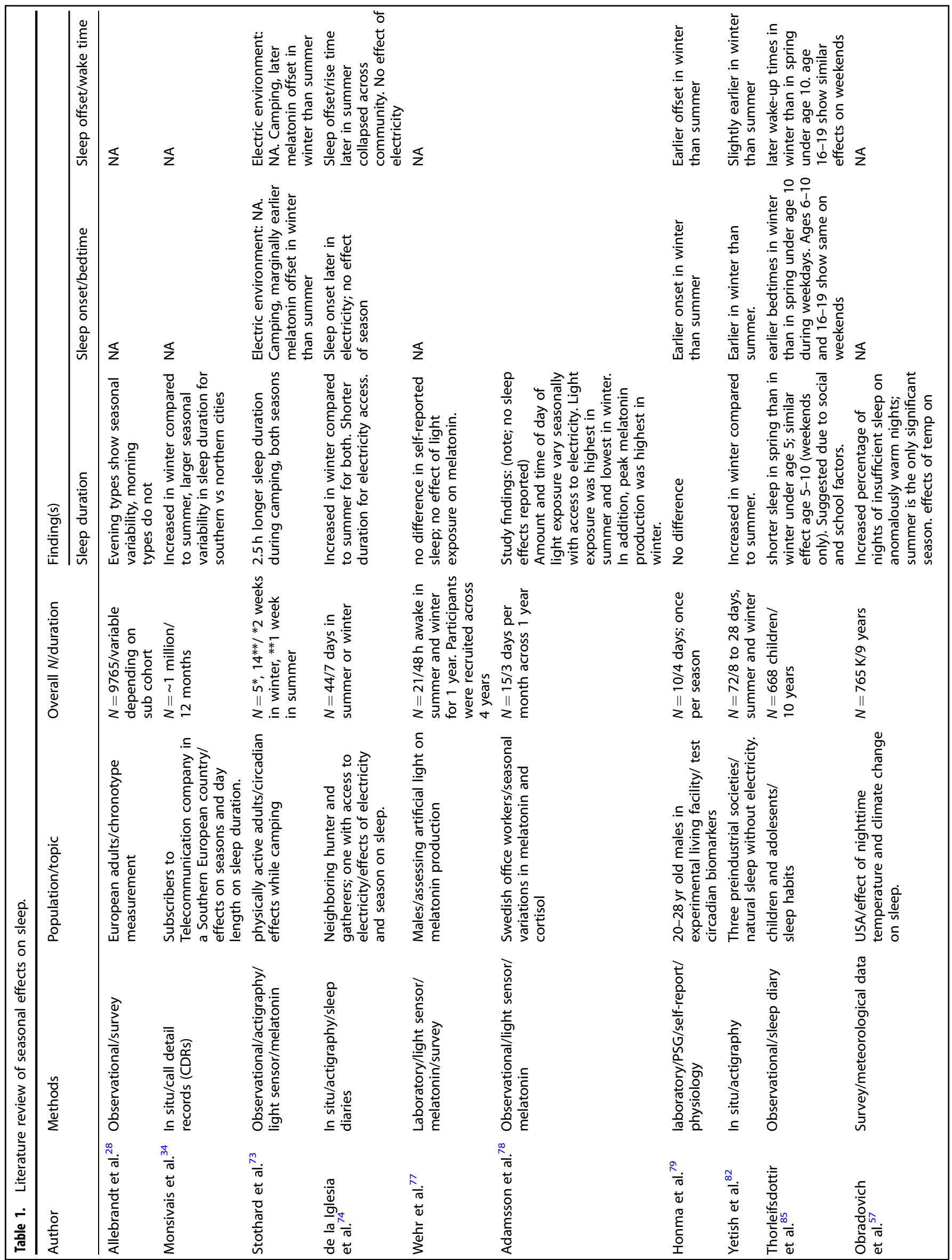




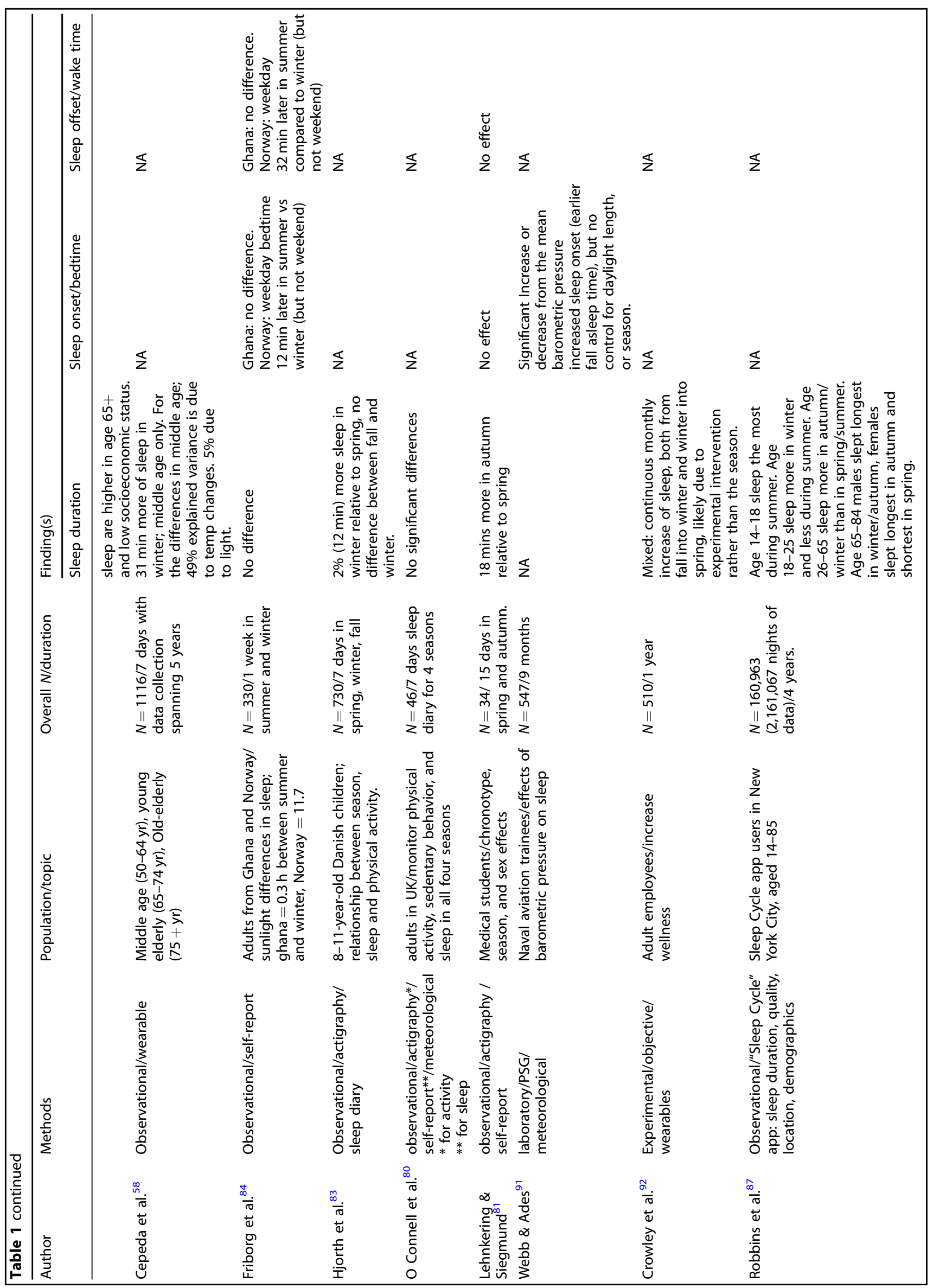




\section{Bedtime}

Bedtime results for each of the nested models are presented in Table 4. In the full model, including demographic, psychological traits, seasonal, and weather variables (Model 3), day length, seasons (spring and summer), temperature weather component, age, openness, and chronotype are statistically significantly associated with bedtime (Table 4), with a fixed-effect variance explained (pseudo- $R^{2}$ ) of 0.12 and conditional variance explained (pseudo- $R^{2}$ ) of 0.30 . The ICC for the full model was 0.22 , indicating that the random effects of participants explained $\sim 22 \%$ of the total variance explained by the model. From the unstandardized beta coefficients (Table 4), in the full model, we see that every extra hour of day length results in bedtimes that are $1.8 \mathrm{~min}$ earlier (95\% C.I. $(-2.4,-0.6), P<0.001)$. Despite this negative effect of day length, there is an offsetting effect of season, such that spring season delays bedtimes by $4.2 \mathrm{~min}(95 \%$ C.I. $(0.6,7.2), P=0.018)$, and summer season delays bedtimes by $6 \mathrm{~min}$ (95\% C.I. $(2.4,9), P=0.001)$ (compared to the winter season). A unit increase in the temperature principal component corresponds to a bedtime $0.6 \mathrm{~min}$ later (95\% C.I. $(0,1.2), P<.001)$. For age effects, each year older is associated with bedtime $0.6 \mathrm{~min}$ earlier ( $95 \%$ C.I. $(-1.2,0), P=0.041$ ), each point higher in Openness, as scored by the BFI-10, is associated with bedtime 11.4 min later ( $95 \%$ C.I. $(1.8,20.4), P=0.022)$, and each point higher in chronotype, as assessed by the MEQ, is associated with a bedtime that is $3 \mathrm{~min}$ earlier (95\% C.I. $(-3.6,-2.4), P<0.001$ ). Comparing all three models, the results suggest that demographic traits, stress, seasonal, and weather variables explain modest amounts of variance in bedtime in our data. Using one-sided F-tests for comparing variance between the models shows that the seasonal model (Model 2) explains significantly more variance in bedtime than the model with demographics and psychological traits $(F=12.04, P<$ $0.001)$. The addition of weather variables included in the full model (Model 3) explains only minimally more variance over the seasonal model (Model 2) $(F=4.66, P=0.003)$. However, the demographics and psychological traits model (Model 1) had the lowest BIC value of all models tested, indicating it is the best-fitting model.

\section{Wake time}

Wake time results for each of the nested models are presented in Table 5. In the full model including demographic, psychological traits, seasonal and weather variables (Model 3), day length, seasons (fall, spring and summer), chronotype score, openness, and the temperature weather, principal components are statistically significantly associated with wake time (Table 5), with a fixedeffect variance explained (pseudo- $R^{2}$ ) of 0.09 and conditional variance explained (pseudo- $R^{2}$ ) of 0.20 . The ICC for the full model was 0.12 , indicating that the random effects of participants explained $\sim 12 \%$ of the total variance explained by the model. From the unstandardized beta coefficients (Table 5), in the full model, we see that every extra hour of day length results in wake times that are 5.4 min earlier $(95 \%$ C.I. $(-6.6,-4.2), P<0.001)$. The effect of the fall season is such that wake times are $1.8 \mathrm{~min}$ earlier $(95 \%$ C.I. $(-4.8,0), P=0.030)$, while for the spring season, wake times are $8.4 \mathrm{~min}$ earlier (95\% C.I. $(-12.8,-4.6), P<0.001)$, and summer season wake times are delayed by $7.8 \mathrm{~min}$ (95\% C.I. (3.6, 11.4 ), $P<.001$ ) (compared to the reference season winter). For each point higher in chronotype, as assessed by the MEQ, wake time was 2.4 min earlier (95\% C.I. $(-3,-1.8), P<0.001)$. For each point increase in Openness ${ }^{94}$ as scored by the BFI-10, wake time was 11.4 min later $(95 \%$ C.I. $(3.6,19.2), P=0.004)$. For each unit increase temperature principal component, wake time was $0.6 \mathrm{~min}$ later $(95 \%$ C.I. $(0,0.6), P<0.001)$. In comparing all three models, the results suggest that demographic, psychological traits, seasonal, and weather variables explained a modest amount of the variance in wake times in our data. Using one-sided F-tests for comparing variance between the models, we see that the seasonal model (Model 2) explains significantly more variance in wake time 
Table 2. Demographic and psychological trait statistics for the participant pool $(N=216)$.

Categorical demographic statistics

Gender

Organization

Supervisor status

$68.1 \%$ (147) male, $31.9 \%$ (69) female

$52.3 \%$ (113) Org O1, 11.1\% (24) Org O2, 9.7\% (21) Org O3, 26.9\% (58) Org U

$75 \%$ (162) non-supervisors, $25 \%$ (54) supervisors

Continuous demographic and psychological trait statistics

\begin{tabular}{|c|c|c|c|c|}
\hline Measure & Min & Max & Mean & Std. dev \\
\hline Age & 21 & 63 & 34.9 & 9.10 \\
\hline Affect balance & -16 & 36 & 17.3 & 8.32 \\
\hline Conscientiousness & 19.17 & 50 & 38.77 & 6.77 \\
\hline Extraversion & 16.67 & 47.5 & 33.33 & 6.64 \\
\hline Agreeableness & 20.83 & 50 & 38.79 & 5.56 \\
\hline psqi & 3 & 17 & 6.52 & 2.12 \\
\hline Chronotype & 28 & 74 & 53.86 & 9.64 \\
\hline
\end{tabular}

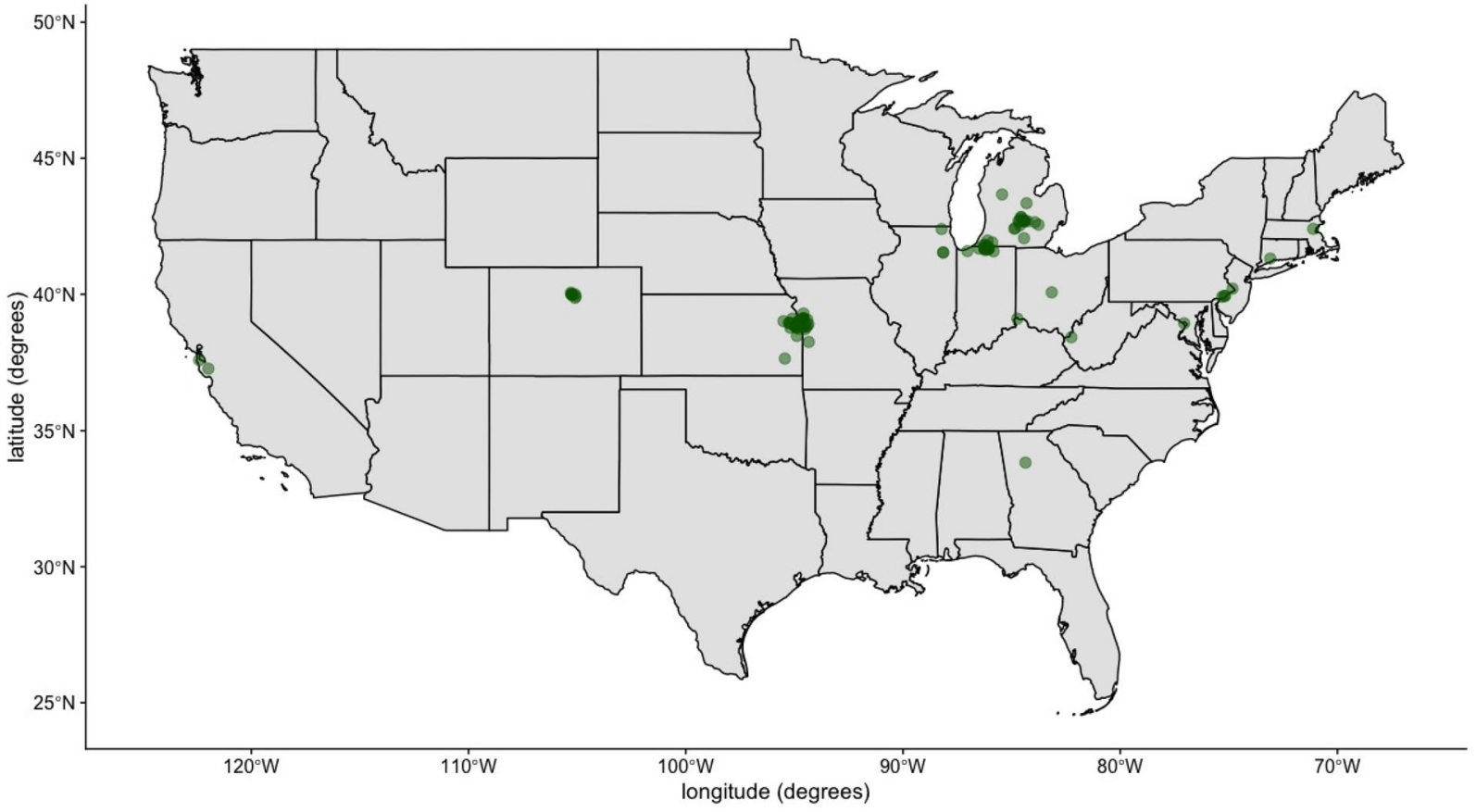

Fig. 1 Geolocations of the participants in the study $(\boldsymbol{N}=\mathbf{2 1 6})$. This map was obtained from the U.S. Census Bureau that permits the free use of the map for publication (https://catalog.data.gov/dataset/2013-cartographic-boundary-file-state-for-united-states-1-20000000).

than the model with demographics and traits $(F=185.81, P<$ 0.001 ), and the addition of weather variables (temperature, wind, and humidity/cloud cover) in the full model (Model 3) explains significantly more variance compared to the model with seasons included (Model 2) $(F=6.23, P<0.001)$. Comparing all three models, we see that the seasonal model (Model 2) had the lowest $\mathrm{BIC}$ value of all models tested indicating that it was the best-fitting model.

\section{DISCUSSION}

We find modest seasonal effects on sleep duration, bedtime, and wake time while controlling for demographics, location, and traits.
Our results, based on a large sample and continuous objective measures, replicate previous work, and show significant demographic and trait predictors of bedtime and wake time, such as age, personality, and chronotype ${ }^{18,21-24,26-34}$. For sleep duration, we found significant negative effects of spring, as reported by Hjorth et al. ${ }^{83}$ and Thorleifsdottir et al. ${ }^{85}$ within children and young adult populations, though our population was adults. In addition, we found significant negative effects of day length similar to Monsivais et al. ${ }^{34}$, de la Iglesia et al. ${ }^{74}$, and Yetish et al. ${ }^{82}$. When examining seasonal effects on bed and wake times, we found the effect of spring to be significantly associated with later bedtimes and earlier wake times, in the same direction as Thorleifsdottir et al. $^{85}$. We also found the effect of summer to be significantly 
a.

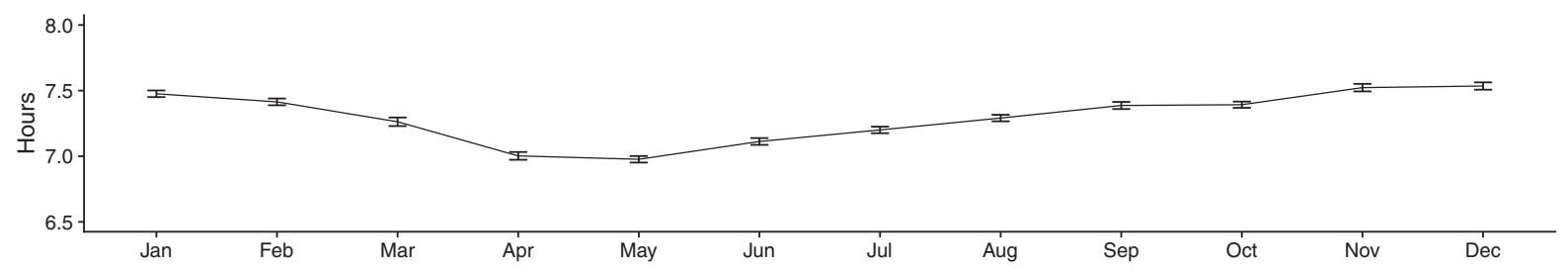

b.

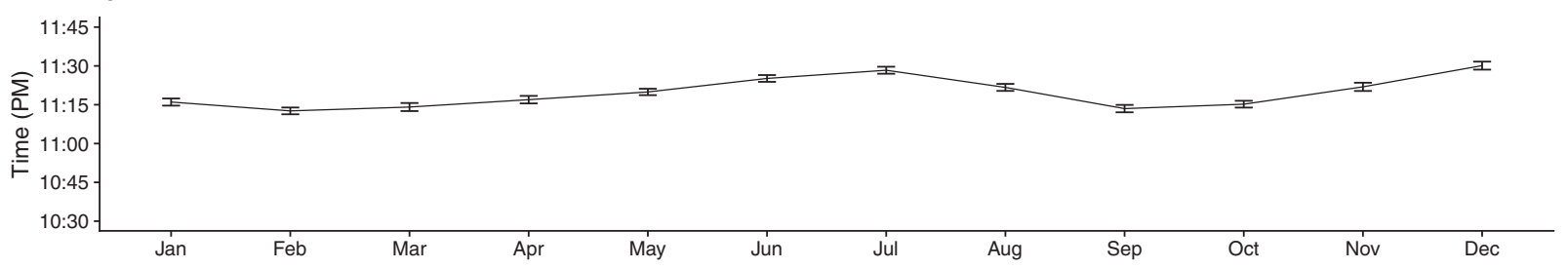

c.

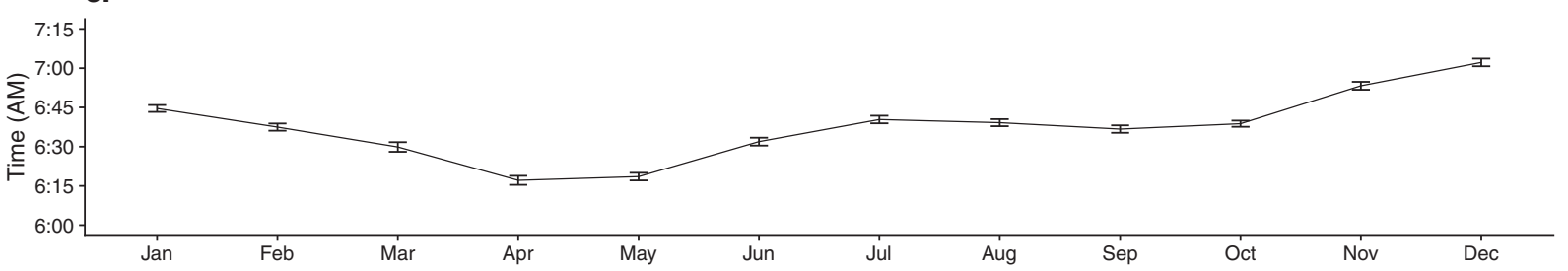

Fig. 2 Sleep parameters per month over the study length. Each point on the graph is produced by filtering all data points that exist for that month and computing the mean of the given sleep metric. Error bars represent the standard error of the mean. a Average monthly adjusted sleep duration. b Average monthy adjusted bedtime. c Average monthly adjusted wake time.

associated with later bedtimes, replicating findings by Thorleifsdottir et al. ${ }^{85}$, Honma et al. ${ }^{79}$, and Yetish et al. ${ }^{82}$, and later wake times similar to Honma et al. ${ }^{79}$ and Yetish et al. ${ }^{82}$. Our results suggest that differences in sleep duration might be more driven by differences in wake time, rather than bedtime, similar to Hashizaki et al. ${ }^{88}$.

In our dataset, spring had an average of 3.6 more hours of day length than winter. Using this day length difference with our unstandardized coefficients, we found that during spring, participants had approximately: 25 min shorter sleep duration, a 25 -min earlier wake time, and a 2 -min earlier bedtime relative to winter. Similarly for summer, with an average of 3.5 more hours of day length than winter, we saw approximately a 12-min shorter sleep duration, a 11-min earlier wake time, and no difference in bedtime relative to winter.

One possible mechanism responsible for the correlation between day length and sleep duration is melatonin, a sleeppromoting hormone. The production of melatonin is tied to light exposure and increased day length; more light inhibits melatonin production while less light increases melatonin production $52,64,66,95,96$. Thus, day length and melatonin should covary seasonally (e.g., as seen in Honma et al. ${ }^{79}$ ). In the industrial world, light and temperature can be artificially controlled and adjusted (especially in indoor spaces) in different seasons. Artificial light may suppress melatonin production, and melatonin may not actually vary seasonally ${ }^{53,77,90,95,97}$, though see ref. ${ }^{78}$. In our study, we demonstrated that seasonal effects (and specifically, day length) are small but still present even in an industrialized nation. We also found a modest effect of the temperature principal component for both bed and wake time. Previous studies examining ambient temperature tend to focus on temperature extremes in the absence of examining day length per se $\mathrm{s}^{57,59-61}$. Cepeda et al. ${ }^{58}$ explicitly examined seasonal effects, temperature, and day length, and found that $49 \%$ of the variance in sleep duration for those aged 50-64 was due to temperature and only
$5 \%$ was due to light changes. However, the authors mention that $30 \%$ of the physical activity in this age group is related to occupation, which can increase exposure to extremes of temperature as in Runkle et al. ${ }^{98}$, and this effect disappears in older individuals. We note that our cohort of information workers primarily worked in offices, and not outdoors. However, while the age range in our sample is fairly large (between 21 and 63), we also did not find a significant effect of age. Our sample is comprised of working adults who are not affected by a seasonal school schedule and dramatic changes in sleep and hormonal systems during puberty, which can contribute to seasonal and age-based sleep effects ${ }^{35,83,85,86}$.

Our results help clarify the findings of past studies. Our study data are based on 51,836 observations from 216 individuals, from 33 days or more in each of the four seasons. While an exact comparison is difficult, our study has at least three times the observations compared to previous wearable-based work, e.g., Cepeda et al. ${ }^{58} n=116,7$ days, Friborg et al. ${ }^{84}, n=330,7$ days, two seasons, and Hjorth et al. ${ }^{83}, n=730,7$ days, three seasons. Our more fine-grained approach demonstrates modest seasonal effects, whereas prior methodologies may not have been sensitive enough to detect these small differences. By using objective, continuous, and long-term sleep data collected in situ within participants across all four seasons, and while controlling for known demographic and psychological confounds, we could detect such differences. Our work can be seen as a link among different findings in prior studies that used different sample characteristics and measures. We controlled for a range of demographic and trait measures along with sleep and weather; it had not been clear from prior work what the effects of these different variables would be in a long-term study. Our relatively large sample enables generalizability of our results to an adult population of college-educated information workers while remaining consistent with some previous work ${ }^{34,74,82,85}$. Our temporal resolution allowed us to test day-to-day weather effects 


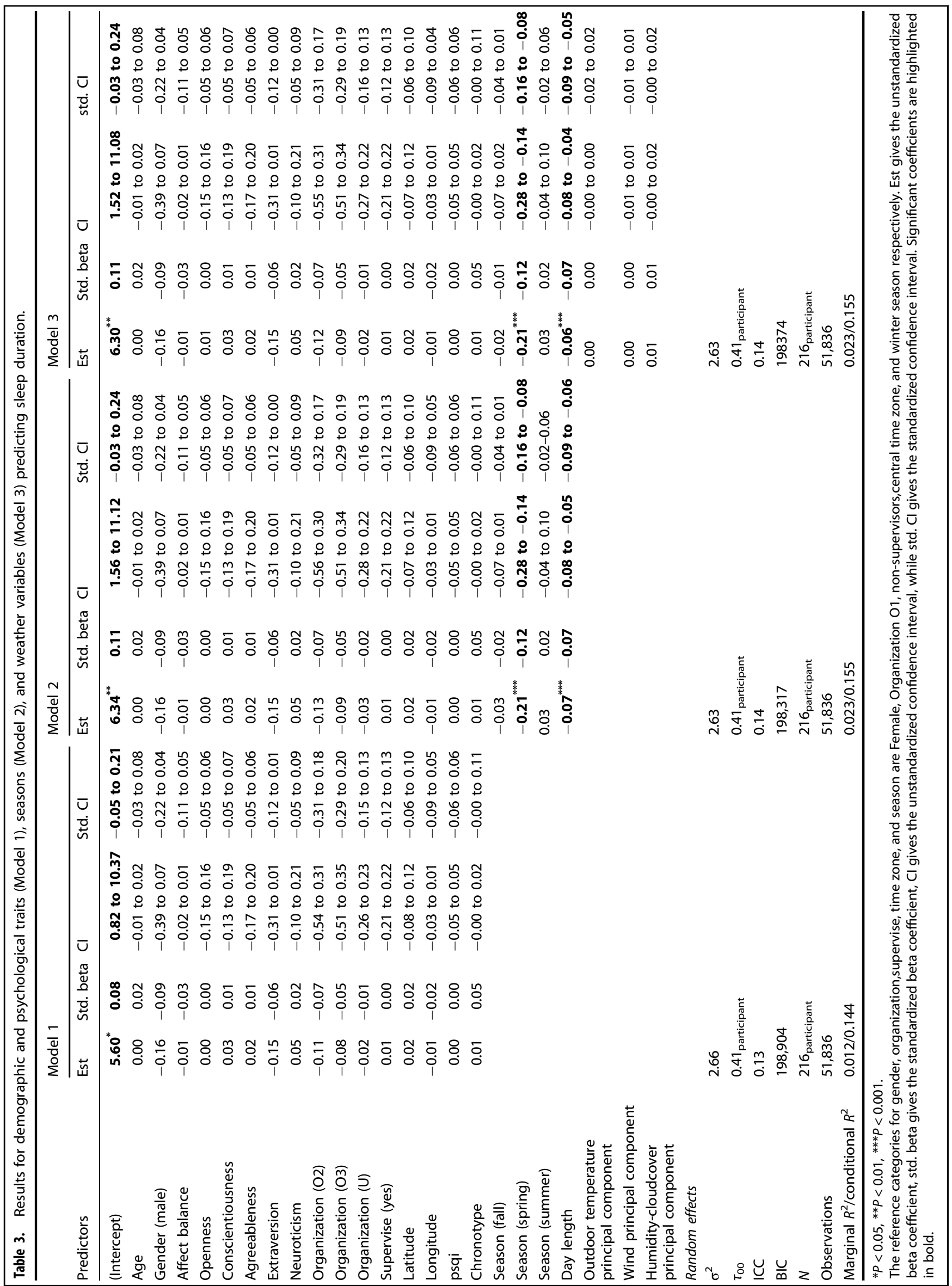




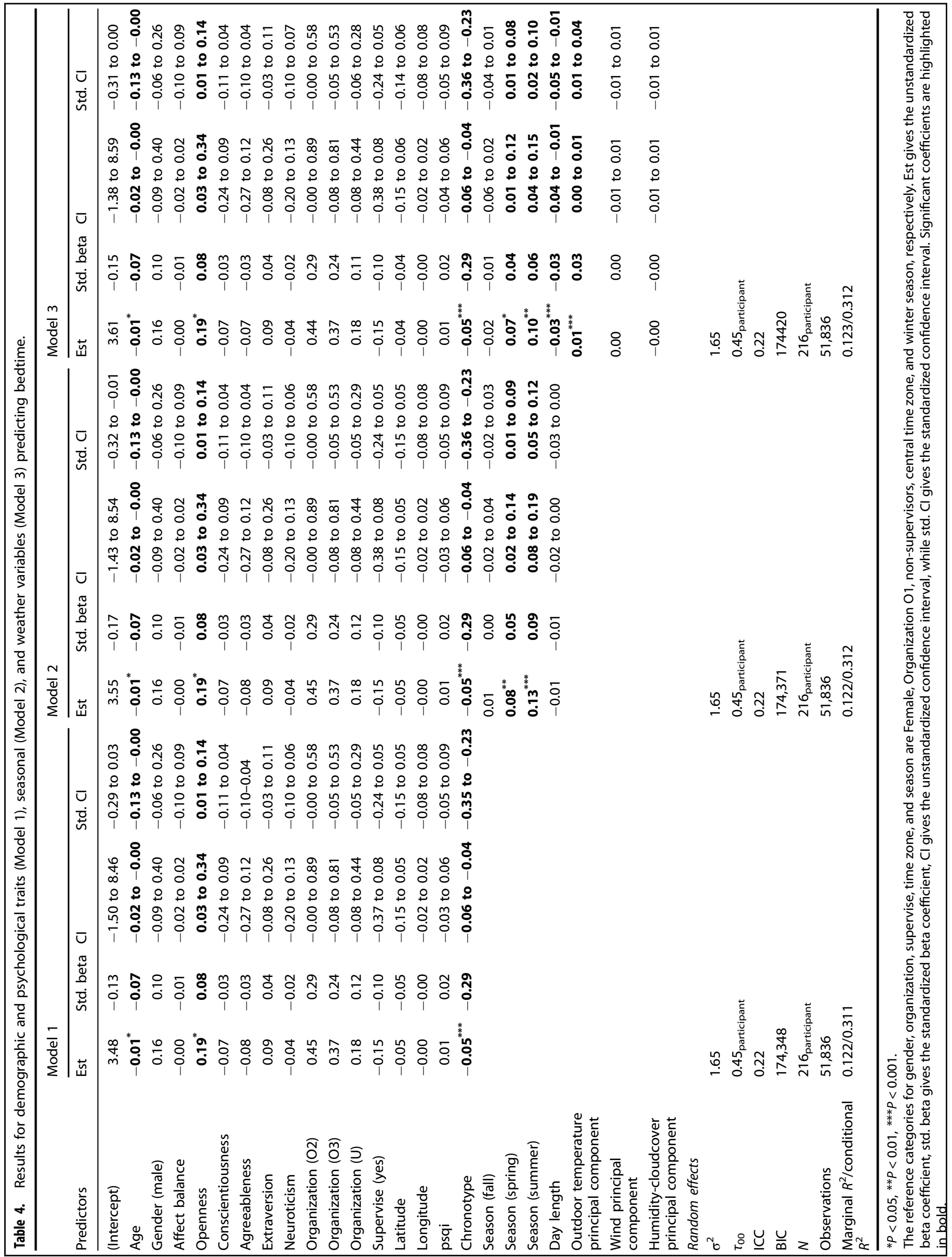




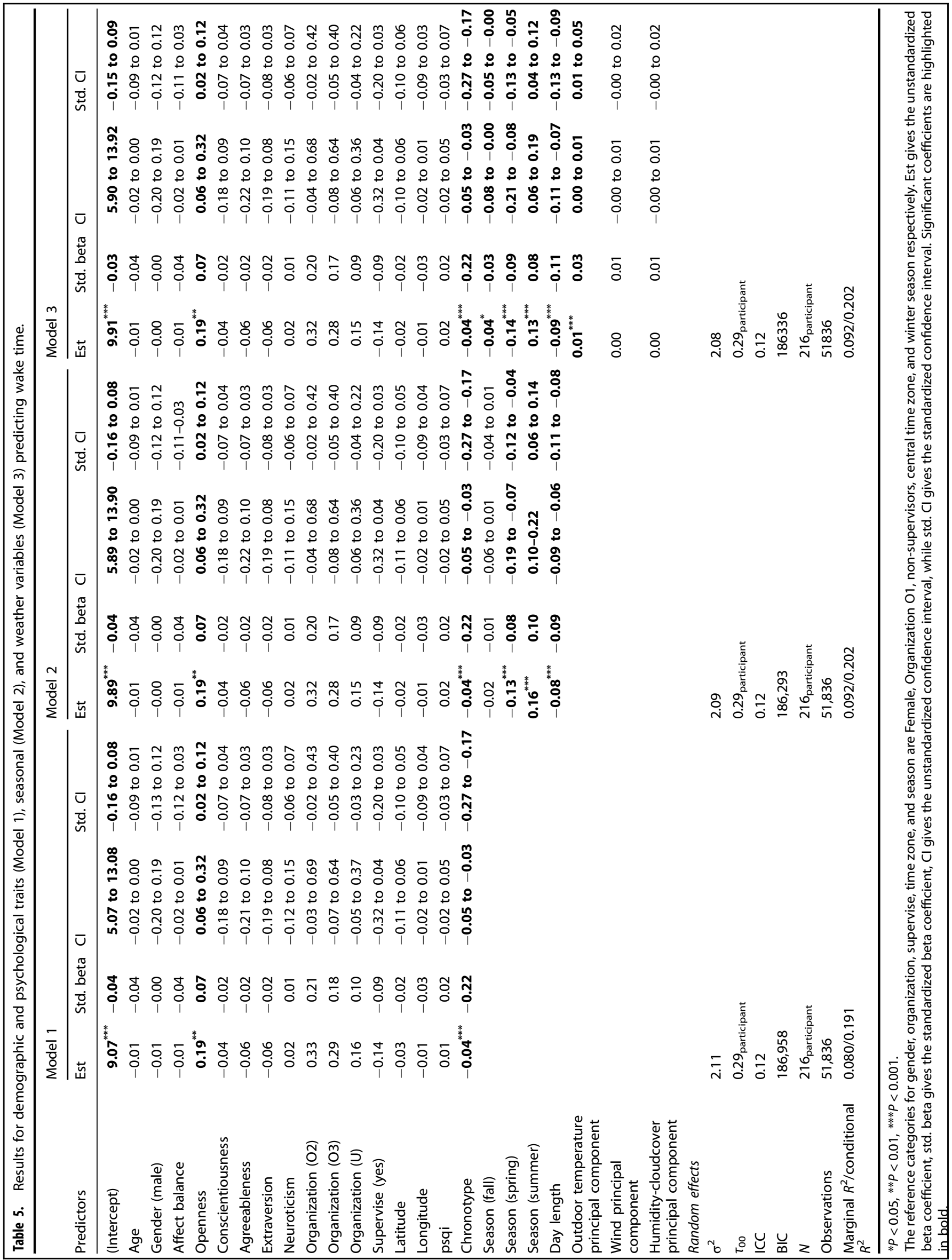


across all seasons and identify that temperature has a small but significant effect, while showing that other weather factors of humidity/cloud cover and wind did not have a significant effect. Our study suggests that future studies of sleep duration, bedtime, and wake time should consider seasonal and daily-level variables such as day length and temperature.

Given the relative importance of season and temperature on sleep compared to other traits and demographic information, future work aimed at optimizing bedtime, wake time, and sleep duration could focus on implications for domains related to health and well-being. For example, seasonal effects may impact those with year-round rigid school and work schedules (e.g., medical interns). Seasonal effects can inform the design of living environments that are totally artificially controlled, e.g., in Arctic stations, submarines, or spacecraft. Smart home designs could also benefit by making allowances for seasonal effects, e.g., by increasing and decreasing lighting and/or temperature on a seasonal basis. Seasonal effects on sleep could be detected in other measurement and usage information, such as network or cell phone data ${ }^{34,87}$, and be used to measure seasonal sleep effects or interventions in the absence of a fitness tracker.

Our study has several limitations. After filtering out participants with inadequate data, the remaining participants in our sample may have been biased in traits (e.g., conscientiousness) associated with better compliance with the study procedures. However, inadequate data could also have been due to technical issues ${ }^{99}$. Our participants were mostly college-educated information workers within the US. Therefore, we can only generalize our results to similar populations. The geographic locations of our participants within the US were spread across a relatively large range of latitudes and longitudes; however, only one participant was on the US west coast. Despite controlling for demographic and trait information of our participants, we were not able to control for exogenous factors (e.g., significant news events, stressful life events, work pressures, or dependents) that may have impacted sleep duration or quality over a period of time. Next, our sample consisted of information workers with flexible work schedules, which may allow more variability in bed and wake times than hourly workers. Another limitation is the use of weather data, rather than personally sensed environmental measurements. Our study cannot comment on how and to what extent participants were exposed to weather, daylight, temperature, and seasonal variation in these constructs. For instance, participants could adapt to cold temperatures with central heating or warmer clothing. However, other wearable sensor studies have determined that light and temperature variations experienced in situ predict bed and wake times ${ }^{100}$, and that these exposures vary seasonally even in controlled environments ${ }^{101}$. While participants may reduce seasonal variability in controlled environments, these efforts do not remove seasonal effects on sleep. Another limitation is the examination of sleep only during the normal work week. Indeed, it may be possible that weekend sleep (which is generally more variable and less subject to social demands) would be more affected by seasonality ${ }^{88}$. Future research should consider how seasonality affects weekends and the difference between weekday and weekend sleep.

The switching of clocks due to seasonal time changes (daylight savings/standard time) could potentially have affected our results. However, we excluded data for the week following daylightsaving time adjustments ${ }^{102-105}$. We also note that work schedules would also have adjusted with the time changes. As we used day length as a measure, adjusting both sunrise and sunset by an hour would result in the same day-length duration. Future studies should consider how sleep changes in response to DST are affected by seasons.

In conclusion, continuous tracking of objective sleep measures over the year shows that seasons do have a modest but significant effect on sleep, even after accounting for known demographic and psychological trait influences. This study helps to clarify differences in past investigations of seasonal effects. Our study suggests the value of using fine-grained temporal resolution in examining environmental effects such as seasons, day length, temperature, and weather on sleep.

\section{METHODS}

\section{Ethics}

This study was approved by the University of Notre Dame's IRB under protocol number 17-05-3870. All participants provided written informed consent prior to taking part in the study.

\section{Demographics and psychological traits}

We control for several demographic (age, sex, organization, supervisory role, latitude, and longitude of home location) and trait measures, known to be associated with sleep behavior ${ }^{18,21-25,27-34}$, collected from a survey at the onset of the study. Psychological traits were measured from validated inventories: Positive and Negative Affect Schedule (PANAS-X) ${ }^{106}$ for affect balance (positive minus negative affect), Big Five Inventory (BFI) ${ }^{94}$ for personality, the Pittsburgh Sleep Quality Index (PSQI) ${ }^{25}$ for sleep quality, and Morning-Eveningness Questionnaire (MEQ) ${ }^{107}$ for chronotype (larger scores indicate more "morning types", smaller scores more "evening types").

\section{Sleep}

To measure sleep, participants wore the Garmin VivoSmart 3 fitness band (24/7) for the year-long duration of the study. Participants' daily sleep durations, bedtimes, and wake times were collected from the Garmin Health API (https://developer.garmin.com/health-api/overview/). Wearables can accurately detect sleep (see refs. ${ }^{108,109}$ ), and we increased sleep measurement accuracy by leveraging phone usage and wearable-derived bedtimes, wake times, and sleep duration (see refs. ${ }^{110,111}$ ).

\section{Weather and seasons}

Daily weather data were collected from the World Weather Online developer API (https://www.worldweatheronline.com/developer/api/) using home location zip codes. Fourteen numeric weather variables were collected (e.g., sunrise/sunset times, temperature (including minimum, maximum, and average), humidity, cloud cover, temperature, wind speed, visibility, and pressure). Principal component analysis to reduce the dimensionality of the data yielded three principal components determined mainly by temperature, wind, and humidity/cloud cover accounting for $71.2 \%$ of the variance in the weather. Day length was calculated from sunrise/sunset times of participants' local locations. Season start dates were defined via astronomical seasons as follows: spring-March 20, summer-June 21, fall-September 22, and winter-December 21 (https:// www.weather.gov/media/ind/seasons.pdf).

\section{Travel}

As travel can result in variable sleep patterns (e.g., change of time zone, schedules) and travel can expose participants to different weather conditions, we excluded participant travel days. The number of entrees of sleep data identified as travel days were 3261 (average of 14.8 days/ person) and were excluded from the final dataset (see the section "Location sensing").

\section{Location sensing}

To determine participant location for weather and travel, we used two Gimbal Series 21 Bluetooth beacons that participants placed in the home and office locations. Beacon sightings recorded by the participants' smartphones determined when they were home or at the office. Gimbal Bluetooth beacons operate in the $2.4-\mathrm{GHz}$ band, allowing them to be sighted in most home and work environments ${ }^{112}$ and up to $100 \mathrm{~m}$ away in unobstructed environments (https://support.gimbal.com/hc/en-us/articles/ 218653567-Customizing-Beacon-Detection-RSSI). Home latitude and longitude are computed using the home beacon location data. Travel is computed using beacon sightings in conjunction with smartphone location data. We defined travel days as when they had both a lack of beacon sightings and a smartphone location more than a 300-mile 
distance from home or an average distance of more than 200 miles away during the day.

\section{Procedures}

Data were collected from 649 individuals (of 757 who started the study) from across the U.S., who completed data collection of approximately a year, from February 5, 2018 to March 15, 2019. The majority of the participants were concentrated in three different organizations (denoted $\mathrm{O} 1, \mathrm{O}$, and O3), and some without a defined organization (denoted U). The characteristics of the participants, sensing streams, and full study details are described in Mattingly et al. ${ }^{111}$. We used data only from weekdays rather than weekends, as weekend sleep is not necessarily reflective of one's normal sleep patterns $\mathrm{s}^{29,113,114}$. We excluded data entries from days where participants were detected to be away from home (see travel calculations above). We also excluded the five weekdays after each daylight savings time (DST) change in our data period (March 11, 2018, November 4, 2018, and March 10, 2019), as DST changes have been shown to generally affect sleep patterns up to a week after the change ${ }^{102-105}$. To account for missing actigraphy data (e.g., dead battery, device not worn) and to ensure adequate data for each participant in each season, we excluded participants who had data for $<50 \%$ of weekdays during any of the four seasons (i.e., at least 33 weekdays per season). We did this rather than impute missing data, as imputed data may introduce a bias for some participants, which may in turn bias our insights ${ }^{115}$. The resulting dataset of 216 participants after this data cleaning had 51,836 observations. Participants had a mean of 239.9 days of data (min: 184, max: 275). Participants had a mean of 61.2 days of data in the winter season (min: 33, max: 84), 57.8 days of data in the fall season (min: 42 , max: 60), 57.1 days of data in the spring season (min: 33, max: 66), and 63.9 days of data in summer season (min: 41 , max: 67).

\section{Analysis}

Previous literature suggests that seasonal effects may occur on bedtime, wake time, or sleep duration independently (see refs. ${ }^{79,81,82}$ ), which led us to run independent models for each variable. As our data consist of repeated observations of sleep data for each participant, we model our data using mixed linear-effect models. We include a random intercept effect on the participant identifier, to predict the daily sleep variables. To address our research questions, we use a hierarchical regression framework to investigate the cumulative variance of sleep duration, bedtime, and wake time using the following nested models: a Baseline (no fixedeffect variables); Model 1, adding demographic and psychological trait variables; Model 2, adding seasonal variables; Model 3, adding weather variables. For predicting bedtime, we used the daily variables (e.g., day length) for the day leading up to a given participant's bedtime. For sleep duration and wake time, we use daily variables from the previous day (i.e., day length from the previous day predicting wake time the following morning). The general equations for the models tested are defined as follows, where $y$ refers to the sleep variable of interest, $y /$ participant refers to the random intercept effect on the participant identifier, $f\left(x_{1}, \ldots, x_{n}\right)=c_{0}+c_{1} x_{1}+\ldots+c_{n} x_{n}$.

Baseline $:=y \mid$ participant $=f(1)$

Model $1:=y \mid$ participant $=f\left(x_{1}, \ldots, x_{14}\right)$

Model $2:=y \mid$ participant $=f\left(x_{1}, \ldots, x_{14}, x_{15}, x_{16}\right)$

Model $3:=y \mid$ participant $=f\left(x_{1}, \ldots, x_{14}, x_{15}, x_{16}, x_{17}, x_{18}, x_{19}\right)$

where the independent variables are

$$
\begin{gathered}
x_{1}:=\text { age, } x_{2}:=\text { gender, } x_{3}:=\text { affect balance, } x_{4}:=\text { openness, } \\
x_{5}:=\text { conscientiousness, }
\end{gathered}
$$

$x_{6}:=$ agreeableness, $x_{7}:=$ extraversion, $x_{8}:=$ neuroticism, $x_{9}:=$ organization,

$x_{10}:=$ supervise, $x_{11}:=$ latitude, $x_{12}:=$ longitude, $x_{13}:=$ psqi, $x_{14}:=$ MEQScore

$x_{15}:=$ season, $x_{16}:=$ day length

$x_{17}:=$ temperature principal component, $x_{18}:=$ wind principal component

$$
x_{19}:=\text { humidity - cloudcover principal component }
$$

For each model, beta coefficients are standardized via the Gelman method whereby the estimates are reduced by dividing them by two standard deviations ${ }^{116}$, in order to allow direct comparison of the strengths of the effects of the variables in the model. All $P$ values and $95 \%$ confidence intervals for beta coefficients are calculated using a parametric bootstrap method in order to ensure model robustness ${ }^{117}$. For all models, a variance inflation factor (VIF) analysis showed the max $\mathrm{GVIF}^{1 /\left(2^{*} \mathrm{Df}\right)}$ for any variable to be 2.80 (day length), indicating acceptable levels of multicollinearity ${ }^{118,119}$. Pseudo $R^{2}$ values for both marginal (fixed effects alone) and conditional (random and fixed) effects are computed using the method described by Nakagawa and Schielzeth ${ }^{120}$. Finally, for each dependent variable (sleep duration, bedtime, and wake time), we also use a model comparison test using Bayesian Information Criterion (BIC). We use BIC to determine the most optimal model accounting for the models' degrees of freedom. The R programming language and packages dplyr ${ }^{121}$, tidyr ${ }^{122}$, lubridate ${ }^{123}, \operatorname{Ime}^{124}$, car $^{125}$, jtools $^{126}$, ggplot $2^{127}, \operatorname{cowplot}^{128}, \mathrm{sf}^{129}$, and $\mathrm{sp}^{130}$ were used for analyses and visualizations.

\section{Reporting summary}

Further information on research design is available in the Nature Research Reporting Summary linked to this article.

\section{DATA AVAILABILITY}

The data that support the findings of this study are available from the corresponding author upon reasonable request.

\section{CODE AVAILABILITY}

The code that supports the findings of this study is available from the corresponding author upon reasonable request.

Received: 22 April 2020; Accepted: 25 February 2021; Published online: 28 April 2021

\section{REFERENCES}

1. Benham, G. Sleep: an important factor in stress-health models. Stress Health 26, 204-214 (2010).

2. Colten, H. R., Altevogt, B. M., Institute of Medicine (U.S.) \& Committee on Sleep Medicine and Research. Sleep Disorders and Sleep Deprivation: an Unmet Public Health Problem (Institute of Medicine: National Academies Press, 2006).

3. Garbarino, S., Lanteri, P., Durando, P., Magnavita, N. \& Sannita, W. Co-morbidity, mortality, quality of life and the healthcare/welfare/social costs of disordered sleep: a rapid review. Int. J. Environ. Res. Public Health 13, 831 (2016).

4. McKnight-Eily, L. R. et al. Relationships between hours of sleep and health-risk behaviors in US adolescent students. Preventive Med. 53, 271-273 (2011).

5. Baum, K. T. et al. Sleep restriction worsens mood and emotion regulation in adolescents. J. Child Psychol. Psychiatry 55, 180-190 (2014).

6. Dinges, D. F. et al. Cumulative sleepiness, mood disturbance, and psychomotor vigilance performance decrements during a week of sleep restricted to $4-5 \mathrm{~h}$ per night. Sleep 20, 267-277 (1997).

7. Golder, S. A. \& Macy, M. W. Diurnal and seasonal mood vary with work, sleep, and daylength across diverse cultures. Science 333, 1878-1881 (2011).

8. Surridge-David, M., MacLean, A., Coulter, M. E. \& Knowles, J. B. Mood change following an acute delay of sleep. Psychiatry Res. 22, 149-158 (1987).

9. Aledavood, T. et al. Smartphone-based tracking of sleep in depression, anxiety, and psychotic disorders. Curr. Psychiatry Rep. 21, 1-9 (2019).

10. Burke, T. M., Scheer, F. A. J. L., Ronda, J. M., Czeisler, C. A. \& Wright, K. P. Sleep inertia, sleep homeostatic and circadian influences on higher-order cognitive functions. J. Sleep. Res. 24, 364-371 (2015).

11. Fullagar, H. H. K. et al. Sleep and athletic performance: the effects of sleep loss on exercise performance, and physiological and cognitive responses to exercise. Sports Med. 45, 161-186 (2015).

12. Lowe, C. J., Safati, A. \& Hall, P. A. The neurocognitive consequences of sleep restriction: a meta-analytic review. Neurosci. Biobehav. Rev. 80, 586-604 (2017).

13. Hafner, M., Stepanek, M., Taylor, J., Troxel, W. M. \& van Stolk, C. Why sleep matters-the economic costs of insufficient sleep: a cross-country comparative analysis. RAND Health Quarterly 6, 11 (2017).

14. Khaleque, A. Effects of diurnal and seasonal sleep deficiency on work effort and fatigue of shift workers. Int. Arch. Occup. Environ. Health 62, 591-593 (1991).

15. Niedhammer, l. et al. Workplace bullying and sleep disturbances: findings from a large scale cross-sectional survey in the French working population. Sleep 32, 1211-1219 (2009).

16. Viola, A. U., James, L. M., Schlangen, L. J. \& Dijk, D.-J. Blue-enriched white light in the workplace improves self-reported alertness, performance and sleep quality. Scand. J. Work Environ. Health 34, 297-306 (2008).

17. Holbein, J. B., Schafer, J. P. \& Dickinson, D. L. Insufficient sleep reduces voting and other prosocial behaviours. Nat. Hum. Behav. 3, 492-500 (2019). 
18. Juda, M., Vetter, C. \& Roenneberg, T. Chronotype modulates sleep duration, sleep quality, and social jet lag in shift-workers. J. Biol. Rhythms 28, 141-151 (2013).

19. Xanidis, N. \& Brignell, C. M. The association between the use of social network sites, sleep quality and cognitive function during the day. Computers Hum. Behav. 55, 121-126 (2016).

20. Aledavood, T., Lehmann, S. \& Saramäki, J. Social network differences of chronotypes identified from mobile phone data. EPJ Data Sci. 7, 46 (2018).

21. Baglioni, C., Spiegelhalder, K., Lombardo, C. \& Riemann, D. Sleep and emotions: a focus on insomnia. Sleep. Med. Rev. 14, 227-238 (2010).

22. Ong, A. D., Kim, S., Young, S. \& Steptoe, A. Positive affect and sleep: a systematic review. Sleep. Med. Rev. 35, 21-32 (2017).

23. Gray, E. \& Watson, D. General and specific traits of personality and their relation to sleep and academic performance. J. Personal. 70, 177-206 (2002).

24. Sano, A. et al. Recognizing academic performance, sleep quality, stress level, and mental health using personality traits, wearable sensors and mobile phones. in Wearable and Implantable Body Sensor Networks (BSN), 2015 IEEE 12th International Conference on 1-6 (IEEE, 2015).

25. Buysse, D. J., Reynolds, C. F., Monk, T. H., Berman, S. R. \& Kupfer, D. J. The Pittsburgh Sleep Quality Index: a new instrument for psychiatric practice and research. Psychiatry Res. 28, 193-213 (1989).

26. Buysse, D. J. et al. Relationships between the Pittsburgh Sleep Quality Index (PSQI), Epworth Sleepiness Scale (ESS), and clinical/polysomnographic measures in a community sample. J. Clin. Sleep. Med. 4, 563-571 (2008).

27. Abdullah, S., Matthews, M., Murnane, E. L., Gay, G., \& Choudhury, T. Towards circadian computing: "early to bed and early to rise" makes some of us unhealthy and sleep deprived. in Proceedings of the 2014 ACM International Joint Conference on Pervasive and Ubiquitous Computing. 673-684 (ACM Press, 2014) https://doi.org/10.1145/2632048.2632100.

28. Allebrandt, K. V. et al. Chronotype and sleep duration: the influence of season of assessment. Chronobiol. Int. 31, 731-740 (2014).

29. Roepke, S. E. \& Duffy, J.F. Differential impact of chronotype on weekday and weekend sleep timing and duration. Nat. Sci. Sleep 2, 213 (2010).

30. Manber, R. \& Armitage, R. Sex, steroids, and sleep: a review. Sleep 22, 540-541 (1999).

31. Mezick, E. J. et al. Influence of race and socioeconomic status on sleep: Pittsburgh SleepSCORE Project. Psychosom. Med. 70, 410-416 (2008).

32. Moore, P. J., Adler, N. E., Williams, D. R. \& Jackson, J. S. Socioeconomic status and health: the role of sleep. Psychosom. Med. 64, 337-344 (2002).

33. Petrov, M. E., Lichstein, K. L. \& Baldwin, C. M. Prevalence of sleep disorders by sex and ethnicity among older adolescents and emerging adults: Relations to daytime functioning, working memory and mental health. J. Adolescence 37, 587-597 (2014)

34. Monsivais, D., Ghosh, A., Bhattacharya, K., Dunbar, R. I. M. \& Kaski, K. Tracking urban human activity from mobile phone calling patterns. PLoS Comput. Biol. 13, e1005824 (2017).

35. Ohayon, M. M., Carskadon, M. A., Guilleminault, C. \& Vitiello, M. V. Meta-analysis of quantitative sleep parameters from childhood to old age in healthy individuals: developing normative sleep values across the human lifespan. Sleep 27, 1255-1273 (2004)

36. Markov, D. \& Goldman, M. Normal sleep and circadian rhythms: neurobiologic mechanisms underlying sleep and wakefulness. Psychiatr. Clin. North Am. 29, 841-853 (2006).

37. Eban-Rothschild, A., Appelbaum, L. \& de Lecea, L. Neuronal mechanisms for sleep/wake regulation and modulatory drive. Neuropsychopharmacology 43, 937-952 (2018).

38. Buckley, T. M. On the interactions of the hypothalamic-pituitary-adrenal (HPA) axis and sleep: normal HPA axis activity and circadian rhythm, exemplary sleep disorders. J. Clin. Endocrinol. Metab. 90, 3106-3114 (2005).

39. Kitamura, S. et al. Estimating individual optimal sleep duration and potential sleep debt. Sci. Rep. 6, 1-9 (2016).

40. Ramakrishnan, S., Wesensten, N. J., Balkin, T. J. \& Reifman, J. A unified model of performance: validation of its predictions across different sleep/wake schedules. Sleep 39, 249-262 (2016).

41. Rajdev, P. et al. A unified mathematical model to quantify performance impairment for both chronic sleep restriction and total sleep deprivation. $J$. Theor. Biol. 331, 66-77 (2013).

42. Borbély, A. A., Daan, S., Wirz-Justice, A. \& Deboer, T. The two-process model of sleep regulation: a reappraisal. J. Sleep. Res. 25, 131-143 (2016).

43. Kräuchi, K. The thermophysiological cascade leading to sleep initiation in relation to phase of entrainment. Sleep. Med. Rev. 11, 439-451 (2007).

44. Reppert, S. M. \& Weaver, D. R. Coordination of circadian timing in mammals. Nature 418, 935-941 (2002).

45. Sharma, V. K. \& Chandrashekaran, M. K. Zeitgebers (time cues) for biological clocks. Anim. Behav. 89, 11 (2005).
46. Dijk, D. \& Czeisler, C. Contribution of the circadian pacemaker and the sleep homeostat to sleep propensity, sleep structure, electroencephalographic slow waves, and sleep spindle activity in humans. J. Neurosci. 15, 3526-3538 (1995).

47. McCormick, D. A. \& Bal, T. Sleep and arousal: thalamocortical mechanisms. Annu. Rev. Neurosci. 20, 185-215 (1997).

48. Daan, S., Beersma, D. G. \& Borbely, A. A. Timing of human sleep: recovery process gated by a circadian pacemaker. Am. J. Physiol.-Regulatory, Integr. Comp. Physiol. 246, R161-R183 (1984).

49. Leppämäki, S., Meesters, Y., Haukka, J., Lönnqvist, J. \& Partonen, T. Effect of simulated dawn on quality of sleep-a community-based trial. BMC Psychiatry $\mathbf{3}$, 1-5 (2003).

50. Van De Werken, M. et al. Effects of artificial dawn on sleep inertia, skin temperature, and the awakening cortisol response: Effects of artificial dawn on sleep inertia, skin temperature and the awakening cortisol response. J. Sleep. Res. 19 425-435 (2010).

51. Thompson, A., Jones, H., Gregson, W. \& Atkinson, G. Effects of dawn simulation on markers of sleep inertia and post-waking performance in humans. Eur. J. Appl. Physiol. 114, 1049-1056 (2014).

52. Duffy, J. F. \& Wright, K. P. Entrainment of the human circadian system by light. J. Biol. Rhythms 20, 326-338 (2005).

53. Blume, C., Garbazza, C. \& Spitschan, M. Effects of light on human circadian rhythms, sleep and mood. Somnologie 23, 147-156 (2019).

54. Gompper, B., Bromundt, V., Orgül, S., Flammer, J. \& Kräuchi, K. Phase relationship between skin temperature and sleep-wake rhythms in women with vascular dysregulation and controls under real-life conditions. Chronobiol. Int. 27, 1778-1796 (2010)

55. Sarabia, J. A., Rol, M. A., Mendiola, P. \& Madrid, J. A. Circadian rhythm of wrist temperature in normal-living subjects. Physiol. Behav. 95, 570-580 (2008).

56. Liedtke, W. B. Deconstructing mammalian thermoregulation. Proc. Natl Acad. Sci. USA 114, 1765-1767 (2017).

57. Obradovich, N., Migliorini, R., Mednick, S. C. \& Fowler, J. H. Nighttime temperature and human sleep loss in a changing climate. Sci. Adv. 3, e1601555 (2017).

58. Cepeda, M. et al. Seasonality of physical activity, sedentary behavior, and sleep in a middle-aged and elderly population: the Rotterdam study. Maturitas 110, 41-50 (2018).

59. Okamoto-Mizuno, K., Tsuzuki, K., Ohshiro, Y. \& Mizuno, K. Effects of an electric blanket on sleep stages and body temperature in young men. Ergonomics 48, 749-757 (2005)

60. Joshi, S. S., Lesser, T. J., Olsen, J. W. \& O'Hara, B. F. The importance of temperature and thermoregulation for optimal human sleep. Energy Build. 131, 153-157 (2016).

61. Harding, E. C., Franks, N. P. \& Wisden, W. The temperature dependence of sleep. Front. Neurosci. 13, 336 (2019).

62. Gilbert, S. S., van den Heuvel, C. J., Ferguson, S. A. \& Dawson, D. Thermoregulation as a sleep signalling system. Sleep. Med. Rev. 8, 81-93 (2004).

63. Kräuchi, K., Cajochen, C. \& Wirz-Justice, A. Waking up properly: is there a role of thermoregulation in sleep inertia? J. Sleep. Res. 13, 121-127 (2004).

64. Cajochen, C., Kräuchi, K. \& Wirz-Justice, A. Role of melatonin in the regulation of human circadian rhythms and sleep: melatonin, sleep and circadian rhythms. J. Neuroendocrinol. 15, 432-437 (2003).

65. González, S. et al. Circadian-related heteromerization of adrenergic and dopamine D4 receptors modulates melatonin synthesis and release in the pineal gland. PLoS Biol. 10, e1001347 (2012).

66. Macchi, M. M. \& Bruce, J. N. Human pineal physiology and functional significance of melatonin. Front. Neuroendocrinol. 25, 177-195 (2004).

67. Furukawa, T., Morrow, E. M., Li, T., Davis, F. C. \& Cepko, C. L. Retinopathy and attenuated circadian entrainment in Crx-deficient mice. Nat. Genet. 23, 466-470 (1999).

68. Vatine, G., Vallone, D., Gothilf, Y. \& Foulkes, N. S. It's time to swim! Zebrafish and the circadian clock. FEBS Lett. 585, 1485-1494 (2011).

69. Ashmore, L. J. \& Sehgal, A. A fly's eye view of circadian entrainment. J. Biol. Rhythms 18, 206-216 (2003).

70. Yuan, Q., Lin, F., Zheng, X. \& Sehgal, A. Serotonin modulates circadian entrainment in Drosophila. Neuron 47, 115-127 (2005).

71. Hurd, M. W. \& Cahill, G. M. Entraining signals initiate behavioral circadian rhythmicity in larval zebrafish. J. Biol. Rhythms 17, 307-314 (2002).

72. Cermakian, N. et al. Light induction of a vertebrate clock gene involves signaling through blue-light receptors and MAP kinases. Curr. Biol. 12, 844-848 (2002).

73. Stothard, E. R. et al. Circadian entrainment to the natural light-dark cycle across seasons and the weekend. Curr. Biol. 27, 508-513 (2017).

74. de la Iglesia, H. O. et al. Access to electric light is associated with shorter sleep duration in a traditionally hunter-gatherer community. J. Biol. Rhythms $\mathbf{3 0}$ 342-350 (2015). 
75. Van Someren, E. J. W. et al. Bright light therapy: improved sensitivity to its effects on rest-activity rhythms in Alzheimer patients by application of nonparametric methods. Chronobiol. Int. 16, 505-518 (1999).

76. Friedman, L. et al. Scheduled bright light for treatment of insomnia in older adults: bright light for insomnia. J. Am. Geriatrics Soc. 57, 441-452 (2009).

77. Wehr, T. A., Giesen, H. A., Moul, D. E., Turner, E. \& Schwartz, P. J. Suppression of men's responses to seasonal changes in day length by modern artificial lighting. Am. J. Physiol. Renal Fluid Electrolyte Physiol. 269, R173-R178 (1995).

78. Adamsson, M., Laike, T. \& Morita, T. Annual variation in daily light exposure and circadian change of melatonin and cortisol concentrations at a northern latitude with large seasonal differences in photoperiod length. J. Physiol. Anthropol. 36, 1-15 (2017).

79. Honma, K., Honma, S., Kohsaka, M. \& Fukuda, N. Seasonal variation in the human circadian rhythm: dissociation between sleep and temperature rhythm. Am. J. Physiol. Regulatory, Integr. Comp. Physiol. 262, R885-R891 (1992).

80. O'Connell, S. E., Griffiths, P. L. \& Clemes, S. A. Seasonal variation in physical activity, sedentary behaviour and sleep in a sample of UK adults. Ann. Hum. Biol. 41, 1-8 (2014).

81. Lehnkering, H. \& Siegmund, R. Influence of chronotype, season, and sex of subject on sleep behavior of young adults. Chronobiol. Int. 24, 875-888 (2007).

82. Yetish, G. et al. Natural sleep and its seasonal variations in three pre-industrial societies. Curr. Biol. 25, 2862-2868 (2015).

83. Hjorth, M. F. et al. Seasonal variation in objectively measured physical activity, sedentary time, cardio-respiratory fitness and sleep duration among 8-11 year-old Danish children: a repeated-measures study. BMC Public Health 13, 1-10 (2013).

84. Friborg, O., Bjorvatn, B., Amponsah, B. \& Pallesen, S. Associations between seasonal variations in day length (photoperiod), sleep timing, sleep quality and mood: a comparison between Ghana $\left(5^{\circ}\right)$ and Norway $\left(69^{\circ}\right)$ : Seasonal variations in sleep patterns. J. Sleep. Res. 21, 176-184 (2012).

85. Thorleifsdottir, B., Björnsson, J. K., Benediktsdottir, B., Gislason, T. \& Kristbjarnarson, H. Sleep and sleep habits from childhood to young adulthood over a 10year period. J. Psychosom. Res. 53, 529-537 (2002).

86. Carskadon, M. A. \& Acebo, C. Parental reports of seasonal mood and behavior changes in children. J. Am. Acad. Child Adolesc. Psychiatry 32, 264-269 (1993).

87. Robbins, R. et al. Four-year trends in sleep duration and quality: a longitudinal study using data from a commercially available sleep tracker. J. Med. Internet Res. 22, e14735 (2020).

88. Hashizaki, M., Nakajima, H., Shiga, T., Tsutsumi, M. \& Kume, K. A longitudinal large-scale objective sleep data analysis revealed a seasonal sleep variation in the Japanese population. Chronobiol. Int. 35, 933-945 (2018).

89. Crowley, S. J., Cain, S. W., Burns, A. C., Acebo, C. \& Carskadon, M. A. Increased sensitivity of the circadian system to light in early/mid-puberty. J. Clin. Endocrinol. Metab. 100, 4067-4073 (2015).

90. Wehr, T. A. Effect of seasonal changes in daylength on human neuroendocrine function. Horm. Res. Paediatr. 49, 118-124 (1998).

91. Webb, W. B. \& Ades, H. Sleep tendencies: effects of barometric pressure. Science 143, 263-264 (1964).

92. Crowley, O., Pugliese, L. \& Kachnowski, S. The impact of wearable device enabled health initiative on physical activity and sleep. Cureus https://doi.org/ 10.7759/cureus.825 (2016).

93. Rifkin, D. I., Long, M. W. \& Perry, M. J. Climate change and sleep: a systematic review of the literature and conceptual framework. Sleep. Med. Rev. 42, 3-9 (2018).

94. Soto, C. J. \& John, O. P. The next Big Five Inventory (BFI-2): developing and assessing a hierarchical model with 15 facets to enhance bandwidth, fidelity, and predictive power. J. Personal. Soc. Psychol. 113, 117-143 (2017).

95. McIntyre, I. M., Norman, T. R., Burrows, G. D. \& Armstrong, S. M. Human melatonin suppression by light is intensity dependent. J. Pineal Res. 6, 149-156 (1989).

96. Gritton, H. J., Kantorowski, A., Sarter, M. \& Lee, T. M. Bidirectional interactions between circadian entrainment and cognitive performance. Learn. Mem. 19, 126-141 (2012).

97. Haim, A. \& Zubidat, A. E. Artificial light at night: melatonin as a mediator between the environment and epigenome. Philos. Trans. R. Soc. B: Biol. Sci. 370, 20140121 (2015).

98. Runkle, J. D. et al. Evaluation of wearable sensors for physiologic monitoring of individually experienced temperatures in outdoor workers in southeastern U.S. Environ. Int. 129, 229-238 (2019).

99. Martinez, G. J. et al. On the quality of real-world wearable data in a longitudinal study of information workers. in 2020 IEEE International Conference on Pervasive Computing and Communications Workshops (PerCom Workshops), Austin, TX, USA, 2020 pp. 1-6. https://doi.org/10.1109/PerComWorkshops48775.2020.9156113.

100. Martinez-Nicolas, A., Ortiz-Tudela, E., Madrid, J. A. \& Rol, M. A. Crosstalk between environmental light and internal time in humans. Chronobiol. Int. 28, 617-629 (2011).

101. Department of the Built Environment, Eindhoven University of Technology, Eindhoven, The Netherlands. et al. Exploring the impact of natural light exposure on sleep of healthy older adults: a field study. J. Daylighting 5, 14-20 (2018).
102. Varughese, J. \& Allen, R. P. Fatal accidents following changes in daylight savings time: the American experience. Sleep. Med. 2, 31-36 (2001).

103. Harrison, Y. The impact of daylight saving time on sleep and related behaviours. Sleep. Med. Rev. 17, 285-292 (2013).

104. Coren, S. Daylight savings time and traffic accidents. N. Engl. J. Med. 334, 924-925 (1996).

105. Kantermann, T., Juda, M., Merrow, M. \& Roenneberg, T. The human circadian clock's seasonal adjustment is disrupted by daylight saving time. Curr. Biol. 17, 1996-2000 (2007).

106. Watson, D. \& Clark, L. A. The PANAS-X: manual for the positive and negative affect schedule-expanded form. https://ir.uiowa.edu/psychology_pubs/11 (1999).

107. Horne, J. \& Ostberg, O. A self-assessment questionnaire to determine morningness-eveningness in human circadian rhythms. Int. J. Chronobiol. 4, 97 (1976).

108. Kang, S.-G. et al. Validity of a commercial wearable sleep tracker in adult insomnia disorder patients and good sleepers. J. Psychosom. Res. 97, 38-44 (2017).

109. Zinkhan, M. et al. Agreement of different methods for assessing sleep characteristics: a comparison of two actigraphs, wrist and hip placement, and selfreport with polysomnography. Sleep. Med. 15, 1107-1114 (2014).

110. Martinez, G. et al. Improved sleep detection through the fusion of phone agent and wearable data streams. in 2020 IEEE International Conference on Pervasive Computing and Communications Workshops (PerCom Workshops), Austin, TX, USA, 2020, pp. 1-6, https://doi.org/10.1109/PerComWorkshops48775.2020.9156211.

111. Mattingly, S. M. et al. The tesserae project: large-scale, longitudinal, in situ, multimodal sensing of information workers. in Extended Abstracts of the 2019 $\mathrm{CHI}$ Conference on Human Factors in Computing Systems-CHI '19 1-8 (ACM Press, 2019).

112. Liu, S., Jiang, Y. \& Striegel, A. Face-to-face proximity estimationusing bluetooth on smartphones. IEEE Trans. Mob. Comput. 13, 811-823 (2014).

113. Giannotti, F., Cortesi, F., Sebastiani, T. \& Ottaviano, S. Circadian preference, sleep and daytime behaviour in adolescence. J. Sleep. Res. 11, 191-199 (2002).

114. Vitale, J. A. et al. Chronotype influences activity circadian rhythm and sleep: differences in sleep quality between weekdays and weekend. Chronobiol. Int. 32, 405-415 (2015)

115. Engels, J. Imputation of missing longitudinal data: a comparison of methods. J. Clin. Epidemiol. 56, 968-976 (2003).

116. Gelman, A. Scaling regression inputs by dividing by two standard deviations. Stat. Med. 27, 2865-2873 (2008).

117. Luke, S. G. Evaluating significance in linear mixed-effects models in R. Behav. Res. Methods 49, 1494-1502 (2017).

118. James, G., Witten, D., Hastie, T. \& Tibshirani, R. An Introduction to Statistical Learning. Vol. 103 (Springer, 2013).

119. O'brien, R. M. A caution regarding rules of thumb for variance inflation factors. Qual. Quant. 41, 673-690 (2007).

120. Nakagawa, S. \& Schielzeth, H. A general and simple method for obtaining $R^{2}$ from generalized linear mixed-effects models. Methods Ecol. Evol. 4, 133-142 (2013).

121. Wickham, H., Francois, R., Henry, L. \& Müller, K. dplyr: a grammar of data manipulation. $R$ Package Version 0.4 3. https://cran.r-project.org/web/packages/ dplyr/ (2015)

122. Wickham, H. \& Henry, L. tidyr: easily tidy data with 'spread ()' and 'gather ()' functions. $R$ Package Version 0.8 2. https://mran.microsoft.com/snapshot/201702-04/web/packages/tidyr/index.html (2018).

123. Grolemund, G. \& Wickham, H., others. Dates and times made easy with lubridate. J. Stat. Softw. 40, 1-25 (2011).

124. Bates, D. et al. Package 'Ime4'. Version 1, 17 (2018).

125. Fox, J. et al. Package 'car'. Vienna: R Foundation for Statistical Computing. https://cran.r-project.org/package $=$ car (2012).

126. Long, J. A. \& Long, M. J. A. Package 'jtools'. https://github.com/jacob-long/jtools (2017).

127. Wickham, H. ggplot2. Wiley Interdiscip. Rev.: Comput. Stat. 3, 180-185 (2011).

128. Wilke, C. O. cowplot: Streamlined Plot Theme and Plot Annotations for "ggplot2". R Package Version 0.9. 4. https://cran.r-project.org/web/packages/cowplot/index. html (2019).

129. Pebesma, E. Simple features for R: standardized support for spatial vector data. R. J. 10, 439-446 (2018).

130. Pebesma, E. \& Bivand, R. S. S classes and methods for spatial data: the sp package. R. N. 5, 9-13 (2005).

\section{ACKNOWLEDGEMENTS}

This research is based on work supported in part by the Office of the Director of National Intelligence (ODNI), Intelligence Advanced Research Projects Activity (IARPA), via IARPA Contract No. 2017-17042800007. The views and conclusions contained herein are those of the authors and should not be interpreted as necessarily representing the official policies, either expressed or implied, of ODNI, 
IARPA, or the U.S. Government. The U.S. Government is authorized to reproduce and distribute reprints for governmental purposes notwithstanding any copyright annotation therein

\section{AUTHOR CONTRIBUTIONS}

A.S. and G.M. designed the study. K.N. and G.J.M. generated additional data. T.G. and P.R.G. conducted the analysis. T.A, T.G., G.M., G.J.M., S.M.M., and P.R.G. performed interpretation of the data. S.M.M., T.A., and G.M. wrote and reviewed the paper. All authors approve the paper for publication.

\section{COMPETING INTERESTS}

The authors declare no competing interests.

\section{ADDITIONAL INFORMATION}

Supplementary information The online version contains supplementary material available at https://doi.org/10.1038/s41746-021-00435-2.

Correspondence and requests for materials should be addressed to S.M.M.
Reprints and permission information is available at http://www.nature.com/reprints

Publisher's note Springer Nature remains neutral with regard to jurisdictional claims in published maps and institutional affiliations. (c) Open Access This article is licensed under a Creative Commons Attribution 4.0 International License, which permits use, sharing, adaptation, distribution and reproduction in any medium or format, as long as you give appropriate credit to the original author(s) and the source, provide a link to the Creative Commons license, and indicate if changes were made. The images or other third party material in this article are included in the article's Creative Commons license, unless indicated otherwise in a credit line to the material. If material is not included in the article's Creative Commons license and your intended use is not permitted by statutory regulation or exceeds the permitted use, you will need to obtain permission directly from the copyright holder. To view a copy of this license, visit http://creativecommons. org/licenses/by/4.0/.

(c) The Author(s) 2021 